\title{
Ethnic origin and lung function of infants born prematurely
}

\author{
Bülend Yüksel, Anne Greenough
}

\begin{abstract}
Background - Ethnic origin has an important influence on the lung function of adults and young children but its effect during infancy, particularly following premature delivery, is unclear.

Methods - The results from infants of pure Afro-Caribbean (subjects) and pure Caucasian (controls) descent, all of whom were born prematurely (median gestational age 28 weeks), were compared. Fifty subjects were each retrospectively matched with a control for gestational age, sex, and requirement for neonatal ventilation. Lung function measurements were performed at similar postnatal ages in each pair. The median postnatal ages of the two groups at the time of study was seven and eight months, respectively. Lung function was assessed by measurement of functional residual capacity (FRC) by a helium gas dilution technique and plethysmographic measurement of thoracic gas volume (TGV) and airways resistance (Raw), from which specific conductance (sGaw) was calculated.
\end{abstract}

Results - No differences were found between the subjects and controls regarding FRC or TGV, but Raw was higher and sGaw lower in the subjects. The mean Raw of the subjects was $50.3 \mathrm{~cm} \mathrm{H}_{2} \mathrm{O} / 1 / \mathrm{s}$ and of the controls was $44.1 \mathrm{~cm} \mathrm{H} \mathrm{H}_{2} \mathrm{O} / 1 / \mathrm{s}(95 \%$ confidence intervals of the difference 1.5 to $10 \cdot 9$ ).

Conclusions - Prematurely born infants of Afro-Caribbean origin have more severe lung function abnormalities at approximately 7-8 months of age than those of Caucasian origin. This merits further investigation.

(Thorax 1995;50:773-776)

Keywords: lung function, ethnic origin, prematurity.

Paediatric

Respiratory

Departments of

Child Health and

Thoracic Medicine

King's College Hospital, London

SE5 9RS

A Greenough

B Yüksel

Reprint requests to: Professor A Greenough.

Received 11 November 1994

Returned to authors

11 January 1995

Revised version received

7 February 1995

Accepted for publication

11 April 1995 and white infants measured in the neonatal period by Stocks et al. ${ }^{3}$ That study included 18 matched pairs of prematurely born infants whose mean gestational age was 33 weeks. Yet, when preterm infants (mean gestational age 35 weeks) were measured at follow up, airways resistance was lower in Afro-Caribbean than in European preterm infants. ${ }^{4}$ It is thus possible that differences in lung function due to ethnic origin, although not present immediately after birth, ${ }^{3}$ may become apparent later in infancy. ${ }^{4}$ The influence of ethnic origin on lung function at follow up of infants born very prematurely, however, is not known.

The incidence ${ }^{56}$ and severity ${ }^{7}$ of respiratory distress syndrome varies between neonates of Afro-Caribbean and Caucasian descent, and these differences are likely to affect lung function at follow up. Thus, if the effect of ethnic origin is to be accurately assessed in a prematurely born population, the patients must be matched not only for gestational age and sex, but also for mechanical ventilation requirement as an index of severity for the initial respiratory illness. We have performed such a matching process using data collected during our prospective follow up study of very prematurely born patients (mean gestational age 28 weeks).

\section{Methods}

PATIENTS

From our prospective follow up study, into which patients were recruited over a period of three years, 59 infants of pure Afro-Caribbean descent (subjects) were identified who had had lung function measurements during the first year of life. We then attempted to match the subjects from a pool of 86 infants of pure Caucasian descent (controls) for gestational age, sex, and requirement for ventilation. In the event of there being more than one control matching a subject, the control whose duration of ventilatory requirement most closely matched the subject was chosen. In addition, the lung function measurements of the subject and control had to have been made at a similar postnatal age - that is, within one month. It was not possible to find controls for nine subjects, all of whom were born very prematurely at 23-27 weeks of gestation. None of the controls had delivered at 23 weeks gestation, thus one subject born at 23 weeks could only be matched with a 24-week gestation control. Both the prospective follow up and intervention studies were approved by King's College Hospital Ethics Committee and parents gave informed consent. 
Table 1 Patient characteristics

\begin{tabular}{lccc}
\hline & $\begin{array}{l}\text { Afro-Caribbean } \\
(n=50)\end{array}$ & $\begin{array}{l}\text { Caucasian } \\
(n=50)\end{array}$ & $p$ \\
\hline Males (n) & 24 & 24 & NS \\
Birthweight (g) & $1138(506-1866)$ & $1094(560-1950)$ & NS \\
Gestational age (weeks) & $28(23-35)$ & $28(24-35)$ & NS \\
Received surfactant (n) & 10 & 11 & NS \\
Ventilated (n) & 42 & 42 & NS \\
Duration of ventilation (days) & $2 \cdot 5(0-63)$ & $4 \cdot 5(0-75)$ & NS \\
Maximum peak inspiratory pressure (cm Ho) & $20(0-35)$ & $20.5(0-31)$ & NS \\
Maximum inspired oxygen concentration (\%) & $50(0-95)$ & $67(0-95)$ & NS \\
Duration of oxygen dependency (days) & $7(0-370)$ & $12(0-180)$ & NS \\
Parental smoking (n) & 12 & 10 & NS \\
Bronchiolitis (n) & 5 & 4 & NS \\
Symptomatic (n) & 29 & 24 &
\end{tabular}

Median (range) values are given where relevant.

\section{STUDY DESIGN}

The smoking habits of the parents were determined and recorded as positive if the parents were smoking at the time of the lung function measurements. As part of the prospective follow up study lung function measurements were made at approximately six monthly intervals

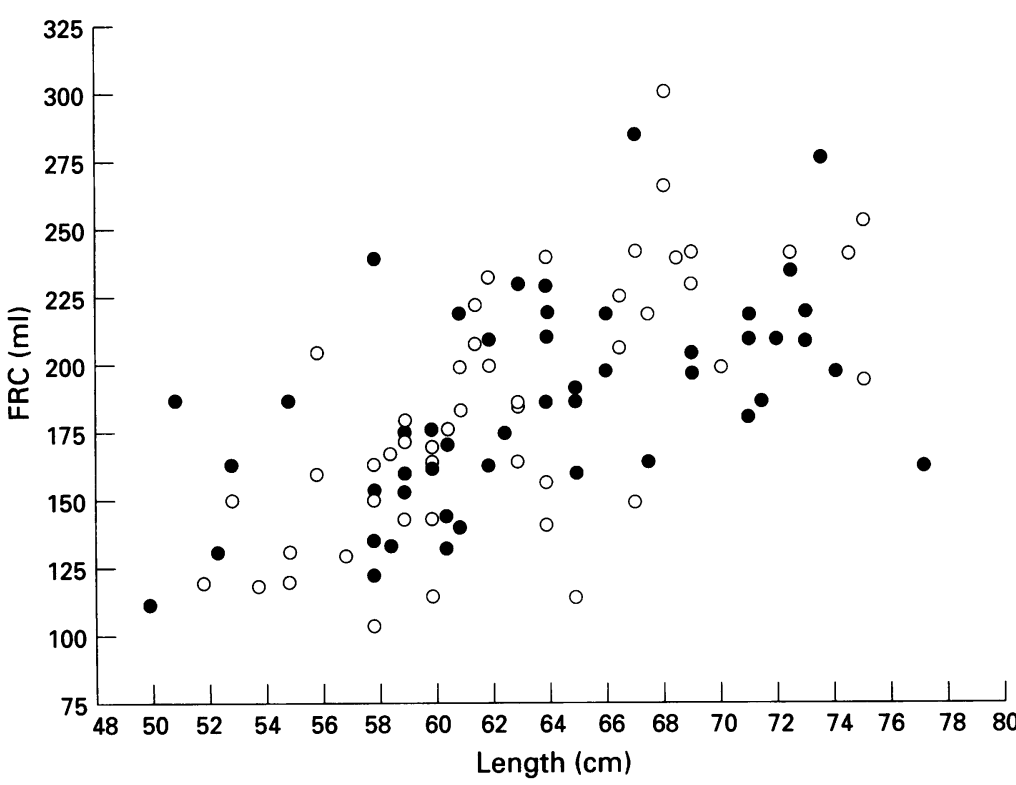

Figure 1 Functional residual capacity $(F R C)(\mathrm{ml})$ versus length $(\mathrm{cm}) . \mathrm{O}=$ AfroCaribbean origin; $\mathrm{O}=$ Caucasian origin. Individual data plotted.

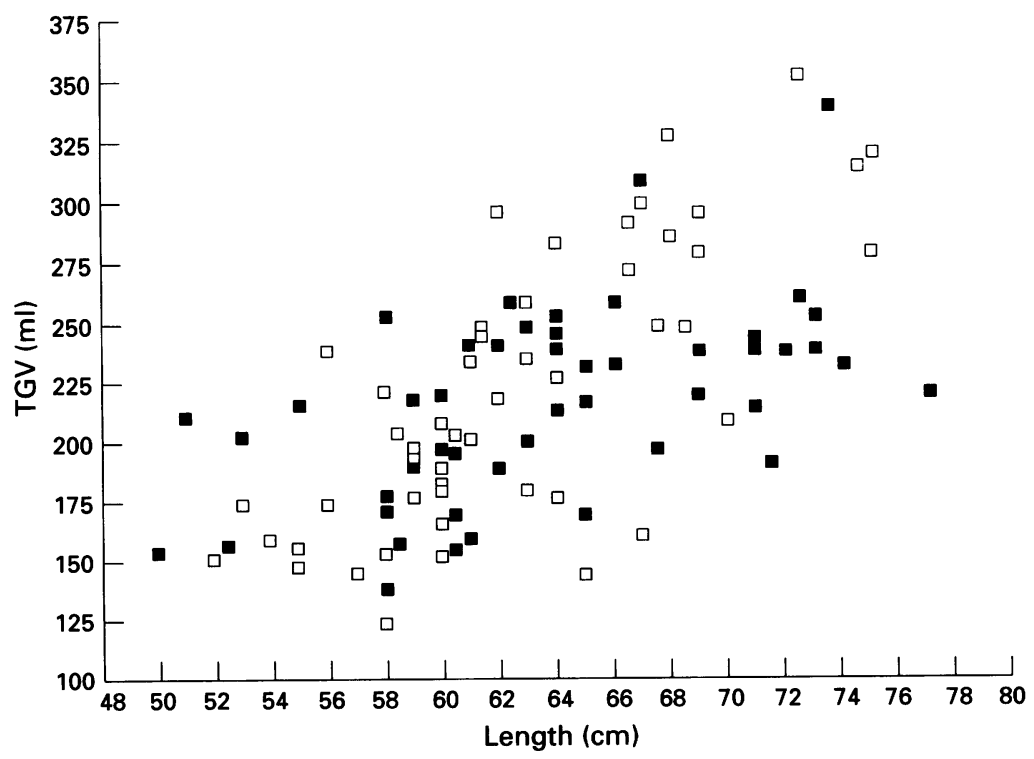

Figure 2 Thoracic gas volume (TGV) (ml) versus length (cm). $\square=$ Afro-Caribbean origin; $\square=$ Caucasian origin. Individual data plotted. during infancy. In addition, diary cards were kept by parents of their child's respiratory problems. For the purposes of this study infants were described as symptomatic if they had wheezed and/or coughed on at least three days per week over a four week period, or at least three days following upper respiratory tract infections during the period between discharge from hospital and the first lung function measurements.

LUNG FUNCTION TESTS

Infants were seen in the Paediatric Respiratory Laboratory where a medical history was taken, height and weight measured, and the infant examined. Sedation was achieved with oral chloral hydrate (80-100 mg/kg) and lung mechanics were measured in the supine position during quiet sleep. Thoracic gas volume (TGV) and airways resistance (Raw) was measured with an infant whole body plethysmograph (Hammersmith Hospital, Department of Medical Engineering) and specific conductance (sGaw) was calculated from these measurements. Functional residual capacity (FRC) was measured by a helium gas dilution technique. The details of TGV, Raw, and FRC measurements have been described previously. ${ }^{8}$ Some of the individual results have already been reported as part of the prospective follow up $^{8-10}$ and intervention ${ }^{11-14}$ studies.

STATISTICAL ANALYSIS

The $95 \%$ confidence intervals of the difference between the means of the lung function results of the two groups were calculated. Differences in the patient characteristics of the two groups were assessed for statistical significance using the Wilcoxon rank sum or $\chi^{2}$ test as appropriate. As the distribution of the differences in lung function between pairs was not skewed, differences between individual subject and control pairs were assessed for statistical significance using the paired $t$ test.

\section{Results}

Fifty Afro-Caribbean and 50 Caucasian infants were studied. There was no significant difference in the characteristics of the two groups (table 1). Twenty two subjects and 19 controls required supplementary oxygen beyond 28 days and, of these, five subjects and four controls had bronchopulmonary dysplasia. ${ }^{15}$ No infant, however, was oxygen dependent at the time of the lung function measurements. There was no significant difference in the number of infants who had bronchiolitis, were symptomatic at follow up, or whose parents smoked (table 1).

There were no significant differences in FRC (fig 1) or TGV (fig 2) between the groups regardless of whether lung volume was related to weight or length (table 2). The Afro-Caribbean infants, however, had higher Raw (fig 3) $(p<0.05)$ and lower sGaw $(p<0.05)$ than the Caucasian infants (table 2). 
Table 2 Lung function results

\begin{tabular}{|c|c|c|c|c|}
\hline & Afro-Caribbean & Caucasian & $\begin{array}{l}95 \% \text { CI of difference } \\
\text { between means }\end{array}$ & $p$ \\
\hline $\begin{array}{l}\text { Postnatal age (months) } \\
\text { Weight at measurement }(\mathrm{kg}) \\
\text { Height at measurement }(\mathrm{cm}) \\
\text { FRC (ml/kg) } \\
\text { TGV }(\mathrm{ml} / \mathrm{kg}) \\
\text { Raw }\left(\mathrm{cm} \mathrm{H} \mathrm{O}_{2}^{-1} \mathrm{~s}^{-1}\right) \\
\text { sGaw }\left(\mathrm{cm} \mathrm{H} \mathrm{H}_{2} \mathrm{O}^{-1} \mathrm{~s}^{-1}\right)\end{array}$ & $\begin{array}{l}8(2) 6-12 \\
6 \cdot 65(1 \cdot 4) 3 \cdot 7-10 \cdot 2 \\
63 \cdot 2(11 \cdot 8) 50-77 \\
28 \cdot 7(5) 20 \cdot 4-40 \cdot 6 \\
33 \cdot 4(5 \cdot 3) 24 \cdot 1-46 \\
50 \cdot 3(11 \cdot 7) 31-96 \\
0.098(0 \cdot 03) 0.054-0 \cdot 232\end{array}$ & $\begin{array}{l}8 \cdot 3(2 \cdot 1) 6-12 \\
6 \cdot 3(1 \cdot 4) 3 \cdot 6-9 \cdot 5 \\
62 \cdot 4(11) 52-75 \\
29 \cdot 3(4 \cdot 6) 19 \cdot 2-40 \cdot 3 \\
35 \cdot 3(5 \cdot 6) 20 \cdot 8-48 \\
44 \cdot 1(12) 22-77 \\
0 \cdot 116(0 \cdot 04) 0.056-0.257\end{array}$ & $\begin{array}{l}-2.51 \text { to } 1.31 \\
-4.06 \text { to } 0.264 \\
1.50 \text { to } 10.9 \\
-0.033 \text { to }-0.003\end{array}$ & $\begin{array}{l}\text { NS } \\
\text { NS } \\
\text { NS } \\
\text { NS } \\
\text { NS } \\
<0 \cdot 05 \\
<0.05\end{array}$ \\
\hline
\end{tabular}

Values are mean (SD) and ranges.

\section{Discussion}

Our finding of a significantly higher Raw and lower sGaw in the Afro-Caribbean infants was surprising as, from previous data, ${ }^{16}$ we might have predicted the reverse. Severity of the respiratory distress syndrome, as determined by the level of respiratory support, influences Raw and sGaw at follow up. ${ }^{9}$ To avoid such a bias we matched the patients for neonatal ventilation requirement. In addition, fortunately there was no significant difference between the maximum peak inspiratory pressure or inspired oxygen concentration of the subjects and controls. It therefore seems unlikely that ethnic variation in the severity of the initial respiratory disease explained our findings. Exogenous surfactant administration affects lung function at follow up. ${ }^{17}$ We did not control for the use of surfactant, but fortunately a similar number of infants in the two groups had been exposed to this treatment.

Specific conductance changes with postnatal age ${ }^{4}$ but we do not feel that this explains our results as matched subjects and controls were of similar postnatal age. In addition, the patients were measured at a time when the change in sGaw with respect to age is relatively small. ${ }^{4}$

Very few of our patients had suffered from bronchiolitis, so our results cannot be explained by the well recognised impact of that illness on subsequent lung function. ${ }^{18}$ There were no significant differences between the two groups in the number of infants whose parents smoked or who were symptomatic at follow up. There

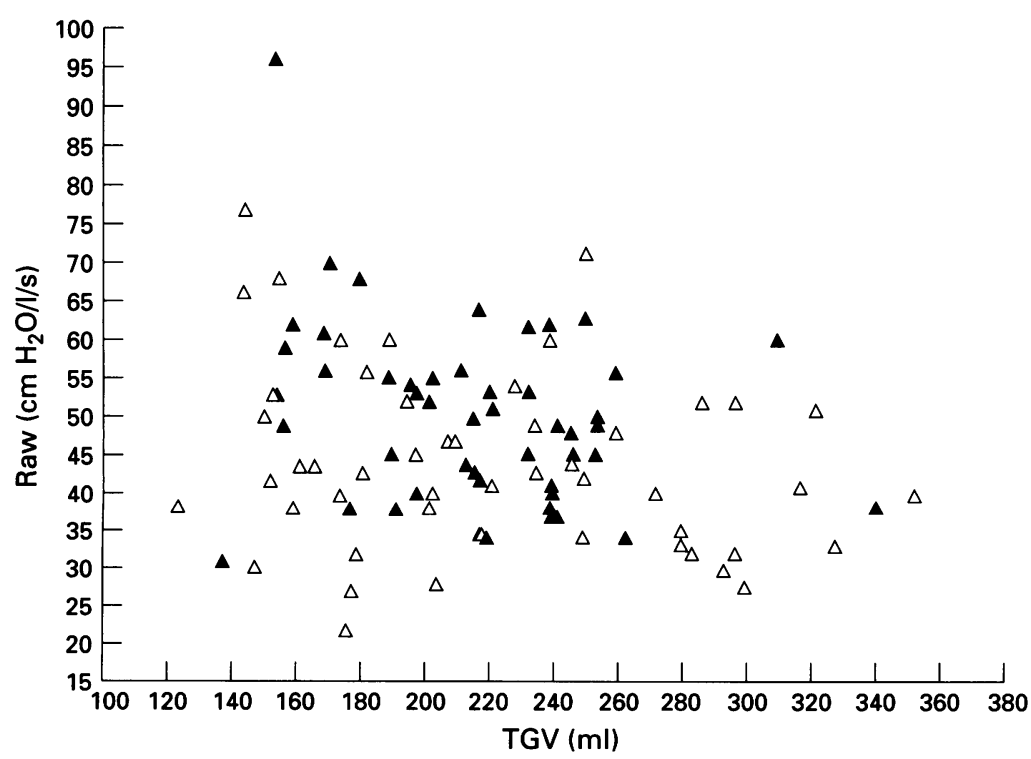

Figure 3 Airways resistance (Raw) $\left(\mathrm{cm} \mathrm{H}_{2} \mathrm{O} / \mathrm{ll} / \mathrm{s}\right)$ versus $T G \mathrm{~V}(\mathrm{ml}) . \mathbf{\Delta}=$ Afro-Caribbean origin; $\triangle=$ Caucasian origin. Individual data plotted. was, however, a trend regarding both factors which was unfavourable to the Afro-Caribbean infants. Both parental smoking ${ }^{19}$ and symptom status $^{20}$ are known to affect lung function at follow up, and these two factors may have acted synergistically to produce a higher Raw in our subjects.

No significant differences were found between the groups in lung volume, either assessed by measurement of TGV or FRC. There was a trend for lower volumes in Afro-Caribbean infants, although this did not reach statistical significance even when the results were related to body length. ${ }^{2}$ This lack of significance may be due to a type II error, as in older children it has been suggested that most of the racial differences in pulmonary function follow from racial differences in lung size. ${ }^{21}$

Previous differences in Raw between ethnic groups have been ascribed to differences in nasal resistance. ${ }^{16}$ In that study, however, only 13 Negro infants and 30 Caucasians were studied, and the two groups were not matched for gestational or postnatal age or requirement for ventilatory support. In addition, the median gestational age ( 35 weeks) of the population was very much higher than that of the present study. The accurate measurement of nasal resistance may be problematical as large differences between individual neonates, ${ }^{22}$ and even between each nasal passage ${ }^{23}$ have been documented. Nevertheless, assessment of nasal resistance in a very immature population would be interesting. If a lower nasal resistance was found in prematurely born patients of AfroCaribbean descent ${ }^{16}$ this would emphasise the difference in airways resistance seen in this study between the two ethnic groups. The aetiology and long term implications of the lung function abnormalities in Afro-Caribbean infants born very prematurely merit further investigation.

Dr B Yüksel is supported by the Medical Research Council. We thank Ms Sue Williams for secretarial assistance.

1 Yang TS, Peat J, Keena V, Donnely P, Unger W, Woolcock A. A review of the racial differences in the lung function of normal Caucasian, Chinese and Indian subjects. Eur Respir ₹ 1991;4:872-80.

2 Pool JB, Greenough A. Ethnic variation in respiratory function in young children. Respir Med 1989;83:123-5.

3 Stocks J, Gappa M, Rabbette PS, Hoo AF, Mukhtar Z, Costeloe KL. A comparison of respiratory function in Afro-Caribbean and Caucasian infants. Eur Respir $\mathcal{F} 1994$; 7:11-6.

4 Stocks J, Godfrey S. Specific airway conductance in relation to post-conceptional age during infancy. $₹$ Appl Physiol to post-conception

5 Bryan H, Hawry Iyshyn P, Hogg-Johnson S, Inwood S, Finley A, D'Costa M, et al. Perinatal factors associated with the respiratory distress syndrome. Am $\mathcal{F}$ Obstet Gynecol 1990;162:476-81.

6 Collaborative Group on Antenatal Steroid Therapy. Effect of antenatal dexamethasone administration on the pre- 
vention of respiratory distress syndrome. Am $\mathcal{f}$ Obstet Gymecol 1981;141:276-86.

7 Wegman ME. Annual summary of vital statistics: 1988. Pediatrics 1989;84:943-56.

8 Yüksel B, Greenough A. Lung function in 6-20 month Yüksel B, Greenough A. Lung function in 6-20 month
old infants born very preterm but without respiratory problems. Pediatr Pulmonol 1992;14:214-21.

9 Yüksel B, Greenough A. Neonatal respiratory support and lung function abnormalities at follow-up. Respir Med 1992; 86:97-100.

10 Yüksel B, Greenough A. Persistence of respiratory symptoms into the second year of life: predictive factors in infants born preterm. Acta Paediatr 1992;81:832-5.

11 Yüksel B, Greenough A. Airway resistance and lung volume before and after bronchodilator therapy in symptomatic preterm infants. Respir Med 1994;88:281-6.

12 Yüksel B, Greenough A. Comparison of the effects on lung function of two methods of bronchodilator administration. Respir Med 1994;88:229-33.

13 Yüksel B, Greenough A. Nebulized sodium cromoglycate in preterm infants - protection against water challenge induced bronchoconstriction. Respir Med 1993;87:37-42.

14 Yüksel B, Greenough A. Variable response to bronchodilator therapy in preterm infants. Respir Med 1993;87:359-64.

15 Northway WH Jr, Rosan RC, Porter DY. Pulmonary disease following respiratory therapy of hyaline membrane disease: bronchopulmonary dysplasia. $N$ Engl $\mathcal{F}$ Med 1967;276: 357-68.

16 Stocks J, Godfrey S. Nasal resistance during infancy. Respir Physiol 1978;34:233-46.

17 Yüksel B, Greenough A, Gamsu HR. Respiratory function at follow-up after neonatal surfactant replacement therapy. Respir Med 1993;87:217-21.

18 Stokes GM, Milner AD, Hodges IGC, Groggins RC. Lung function abnormalities after acute bronchiolotis. $\mathcal{F}$ Pediat 1981;98:871-4.

19 Haurahan JP, Tager IB, Segal MR, Tosteson TD, Castile RG, Vunakis HV, et al. The effect of maternal smoking during pregnancy on early infant lung function. Am Rev during pregnancy on early infant

20 Yüksel B, Greenough A. Relationship of symptoms to lung function abnormalities in preterm infants at follow-up. Pediatr Pulmonol 1991;11:202-6.

21 Coultas DB, Gong H, Grad R, Handler A, McCurdy SA Player $R$, et al. Respiratory diseases in minorities of the United States. Am $\mathcal{f}$ Respir Crit Care Med 1994;149. S93-131.

22 Polgar G, Kong GP. The nasal resistance of newborn infants. F Pediatr 1965;67:557-67.

23 Lacourt G, Polgar G. Interaction between nasal and pulmonary resistance in newborn infants. $\mathcal{F}$ Appl Physiol 1971; 30:870-3. 